\title{
Sex-specific activity of hesperidin, diosmin and genistein on human umbilical vein
}

\author{
Christian Pinna ${ }^{1 *}$ and Angelo Sala ${ }^{1,2}$ \\ ${ }^{1}$ Department of Pharmacological Sciences, University of Milan, via Mangiagalli 25, 20133 Milano, Italy \\ ${ }^{2}$ IBIM, National Research Council, Via Ugo la Malfa 153, 90146 Palermo, Italy
}

\begin{abstract}
Flavonoids intake may be associated to beneficial effects on the cardiovascular system. Aim of this study was to investigate biological activities and mechanism of action of two Citrus-derived flavonoids, hesperidin and diosmin, and the estrogenic isoflavone genistein on vascular tone of human umbilical vein (HUV). Umbilical cords obtained at delivery from healthy women were divided into two groups according to the sex of the new-born. Experiments with flavonoids were carried out

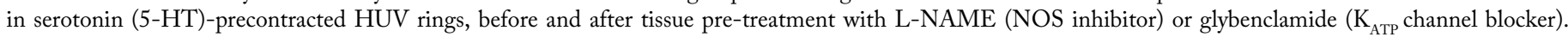
Hesperidin and genistein evoked larger NO-dependent vasorelaxation than diosmin. Endothelium-dependent responses to hesperidin and genistein, but not to diosmin, were gender-specific, being larger in female- as compared with male-derived HUV. Pre-exposure of tissues to L-NAME significantly impaired relaxant responses to hesperidin and genistein and completely blocked those to diosmin. Residual vasorelaxations elicited by hesperidin and genistein after L-NAME pretreatment were blocked by incubation with glybenclamide.
\end{abstract}

In conclusion, while all flavonoids studied evoked NO-dependent vasorelaxation in HUV rings, the effects of hesperidin and genistein were gender-specific and greater than that of diosmin. Hesperidin, diosmin, and genistein might exert a beneficial effect on the vascular and endothelial function of HUV. This information may be important for foetal medicine and practice regarding the effects on foetal development of umbilical vascular functions.

\section{Introduction}

Natural polyphenols are the most common dietary antioxidants abundantly present in many fruits, vegetables and seeds; they exert a wide range of beneficial effects related to the prevention or the modulation of chronic diseases including gestational diabetes [1] and cardiovascular disease [2]. Observational studies have also shown an inverse correlation between the consumption of some classes of polyphenols and risk of stroke [3]; furthermore, preeclampsia occurred more frequently among women who rarely consumed daily serving of fruit and vegetables during pregnancy [4].

Polyphenols prevent endothelial dysfunction improving the release of NO $[5,6]$ and protect cell constituents against oxidative damage [7]. Appropriate antioxidant capacity could prevent or attenuate the severity of those disorders induced by oxidative stress, such as preeclampsia [8] and intrauterine growth restriction [9]. Hesperidin is the predominant flavonoid found in many citrus species and it is presumed to have a role in the vascular protective effects of several citrus products and beverages in humans $[10,11]$.

A recent clinical trial reported that 4-week consumption of orange juice ( $500 \mathrm{ml} /$ day) as well as of control drink plus hesperidin resulted in a significantly decrease of diastolic blood pressure in healthy volunteers [12].

However, little is known about flavonoid-induced activity on human umbilical vein (HUV) [12] and no conclusive results or clear evidence have been still obtained to support their use during gestation [13-15]. Many hypotheses have been considered for the lack of activity of flavonoids at vascular placental circulation; for instance, not all flavonoids have biological activity on endothelial cells [16] or cross the placental barrier. In addition, anatomical and physiological characteristics of HUV are significantly different from other venous vessels; it carries oxygenated blood from placenta to fetus and the vascular tone is not under nervous control [17]. Furthermore, acetylcholine as well as histamine mediate vasocontraction instead of vasodilation as observed in almost all kinds of intact blood vessels [18].

Thus, the present study was designed to elucidate if Citrusderived flavonoids hesperidin and diosmin had vasorelaxant activity on HUV, and in addition if their responses were sex-specific. Results were compared with those to genistein, an estrogen-like isoflavone contained in soya shoots but also widely distributed in leguminous plant foods such as beans, lentils and green peas.

\section{Materials and methods}

Human umbilical cords were collected by the local Hospital Macedonio Melloni (20129, Milan). Informed consent was provided according to the Declaration of Helsinki and the use was approved by the Ethics Committee at the University of Milan.

\section{Ex-vivo experiments on isolated human umbilical vein rings}

The umbilical cords were obtained from anonymous healthy pregnancy women $(\mathrm{N}=90,37-41$ weeks $)$ after delivery and were kept

*Correspondence to: Christian Pinna, Department of Pharmacological Sciences, University of Milan, via Mangiagalli 25, 20133 Milano, Italy, Tel: +390250318258; E-mail: hristian.pinna@unimi.it

Key words: foetal medicine, estrogenic isoflavone genistein, umbilical vascular functions, NO-dependent vasorelaxation

Received: December 02, 2019; Accepted: December 16, 2019; Published: December 19, 2019 
at $5^{\circ} \mathrm{C}$ until the experiment, usually the same day of delivery. A rapid disruption of endothelium associated to increased response to 5-HT and absence of vasorelaxant responses were observed in preparations the day after delivery.

Umbilical cords were divided into male- and female-derived according to the sex of new-born. Medial segment of umbilical vein was carefully isolated from adherent connective tissue and cut into 4-5 mm long rings. From each vein, up to six vascular rings were prepared; care was taken not to touch the endothelial cell layer during the preparations of the HUA rings and thus it was assumed that the endothelium remained undamaged. The rings were mounted in $5 \mathrm{ml}$ organ baths and perfused with Krebs solution $(118 \mathrm{mM} \mathrm{NaCl}, 4.7$ $\mathrm{mM} \mathrm{KCl}, 1.2 \mathrm{mM} \mathrm{KH}_{2} \mathrm{PO}_{4}, 1.1 \mathrm{mM} \mathrm{MgSO}_{4}, 2.5 \mathrm{mM} \mathrm{CaCl}_{2}, 25 \mathrm{mM}$ $\mathrm{NaHCO}_{3}, 5.5 \mathrm{mM}$ glucose, $\mathrm{pH} 7.4$ ) at $37^{\circ} \mathrm{C}$, continuously bubbled with $95 \% \mathrm{O}_{2}$ and $5 \% \mathrm{CO}_{2}$. Tension was recorded using a PowerLab/8SP (ADInstruments, UK) connected to isometric force transducers. Tissues were equilibrated for $1 \mathrm{~h}$ under a resting tension of $2.0 \mathrm{~g}$. Preliminary experiments were performed to verify that 5-hydroxytryptamine $(5-\mathrm{HT})$ at $1 \mu \mathrm{M}$ (approximate $\mathrm{EC}_{80}$ concentration) induced a stable and long-lasting contraction of the preparations. Upon recovery of a stable basal tone, concentration-response curves were obtained by cumulative addition of $\mathrm{U} 46619$ (thromboxane mimetic) $\left(10^{-9}\right.$ to $10^{-6}$ $\mathrm{mol} / \mathrm{l})$, histamine $\left(10^{-8}\right.$ to $\left.10^{-4} \mathrm{~mol} / \mathrm{l}\right), 5-\mathrm{HT}\left(10^{-9}\right.$ to $\left.10^{-4} \mathrm{~mol} / \mathrm{l}\right)$, ATP $\left(10^{-7}\right.$ to $\left.10^{-3} \mathrm{~mol} / \mathrm{l}\right)$, adrenaline $\left(10^{-8}\right.$ to $\left.10^{-4} \mathrm{~mol} / \mathrm{l}\right)$, angiotensin-II $\left(10^{-10}\right.$ to $\left.10^{-6} \mathrm{~mol} / \mathrm{l}\right)$. Concentration-response curves to vasodilatory agonists: adenosine $\left(10^{-9}\right.$ to $\left.10^{-5} \mathrm{~mol} / \mathrm{l}\right)$, sodium nitroprussiate $\left(10^{-9}\right.$ to $\left.10^{-6} \mathrm{~mol} / \mathrm{l}\right)$, different flavonoids $\left(10^{-8}\right.$ to $\left.3 \times 10^{-4} \mathrm{~mol} / \mathrm{l}\right)$, $\beta$-estradiol $\left(10^{-9}\right.$ to $3 \times 10^{-5}$ $\mathrm{mol} / \mathrm{l})$, were obtained in endothelium-intact preparations of the HUA, after development of stable tone by $5-\mathrm{HT}\left(\mathrm{EC}_{80}\right)$. Each preparation was challenged with one agonist only, and time controls were carried out to ensure that responses were reproducible. Concentration-response curves to $\beta$-estradiol in the absence and presence of a competitive ER $\alpha$ - and ER $\beta$-antagonist (ICI 182,780) were carried-out in male- and female-derived HUV. The affinity of ICI 182,780 for estrogen receptors was estimated by the $\mathrm{pA}_{2}$ value, calculated by Schild regression analysis with the program GraphPad Prism 5.0.

Contractile responses to agonists were measured as increase in tone above baseline ( $\mathrm{mN} / \mathrm{mg}$ tissue), whereas relaxant responses were expressed as percentage of relaxation on 5-HT- precontracted tissues.

A separate set of experiments were carried out using preparations devoid of endothelium. The removal of endothelium was obtained by gentle scraping the lumen of umbilical vein ring with a needle (size: 1 $\mathrm{mm}$ ), and its absence was assessed by an increased vasoconstriction to 5 -HT and by the lack of vasodilation to hesperidin $(1 \mu \mathrm{M})$.

\section{Drugs and chemicals}

Acetilcholine hydrochloride, adrenaline hydrochloride, adenosine, 17 $\beta$-estradiol, glybenclamide, histamine, ICI 182,780, Nitro-Larginine methyl ester hydrochloride (L-NAME), sodium nitroprusside (SNP), 5-hydroxytryptamine (5-HT), 9,11-Dideoxy-11a,9aepoxymethanoprostaglandin F2a (U46619), hesperidin, genistein, diosmin, were purchased from Sigma-Aldrich. All compounds were freshly dissolved in distilled $\mathrm{H}_{2} \mathrm{O}$, except flavonoids which were dissolved in DMSO.

\section{Statistical analysis}

All data were expressed as mean \pm S.E.M. of eight experiments and represent unpaired data. Concentration-response curves were fitted and compared by analysis of variance (ANOVA) using GraphPad Prism
5.0. If $P$ values were less than 0.05 the treatment affected the response over the tested range of concentration [19]. Maximal responses and $p \mathrm{D}_{2}$ values $\left(-\log \mathrm{EC}_{50}\right.$ ) for each agonist were compared by one-way ANOVA followed by Tukey's post hoc test using GraphPad InStat.

\section{Results}

\section{Autacoids with contractile activity}

Many autacoids including histamine and neurotransmitters such as ACh caused concentration-dependent constriction in HUV (Figure 1) at resting tone. The stable thromboxane- $\mathrm{A}_{2}$ agonist U46619 $\left(10^{-9}\right.$ to $10^{-6} \mathrm{~mol} / \mathrm{l}$ ) elicited larger concentration-dependent contractions than those evoked by histamine $\left(10^{-8}\right.$ to $\left.10^{-4} \mathrm{~mol} / \mathrm{l}\right), 5-\mathrm{HT}$ ( $10^{-9}$ to $10^{-4}$ $\mathrm{mol} / \mathrm{l})$ and ATP $\left(10^{-7}\right.$ to $\left.10^{-3} \mathrm{~mol} / \mathrm{l}\right)$. However, U46619 caused long lasting vasoconstrictions of HUV preparations which did not return at resting tone even after several washes with fresh Krebs solution. The concentration-response curve to U46619 significantly differed from curves to exogenous serotonin $(P=0.01, n=8)$, histamine $(P=0.005, n=8)$ and ATP $(P=0.001, n=8)$. Tissue sensitivity expressed as the $\mathrm{pD}_{2}$ value between U46619 $(6.94 \pm 0.14 ; n=8)$ and 5 -HT $(6.68 \pm 0.11 ; n=8)$ was comparable, but differed significantly from those of histamine (5.66 $\pm 0.04 ; n=8)$ and ATP $(4.08 \pm 0.04 ; n=8)$. No significant differences between vasoconstrictions in female- and male-derived HUV were observed. Adrenaline $\left(10^{-8}\right.$ to $\left.10^{-4} \mathrm{~mol} / \mathrm{l}\right)$ and angiotensin-II $\left(10^{-10}\right.$ to $10^{-6} \mathrm{~mol} / \mathrm{l}$ ) did not induce contractile responses at the concentrations tested, whereas acetylcholine induced vasoconstriction at resting tone.

\section{Vasorelaxant effects of exogenous sodium nitroprusside and adenosine}

The NO donor, sodium nitroprusside (SNP) added cumulatively $\left(10^{-9}\right.$ to $\left.10^{-5} \mathrm{~mol} / \mathrm{l}\right)$ to the 5 -HT-constricted HUV rings produced endothelium-independent vasorelaxations that were not gender specific (Figure 2). Tissue sensitivity to $\mathrm{SNP}$, expressed as the $\mathrm{pD}_{2}$ was comparable in female- $(6.54 \pm 0.10)$ and in male-derived tissues $(6.86 \pm 0.28)$.

Adenosine (ADO, $1 \mathrm{nM}-10 \mu \mathrm{M}$ ) induced concentration-dependent relaxations on 5-HT-precontracted rings of HUV (Figure 2); tissue sensitivity to $\mathrm{ADO}$, expressed as the $\mathrm{pD}_{2}$ was $(6.54 \pm 0.10)$. On the contrary, acetylcholine ( $\mathrm{ACh}, 10^{-7}$ to $\left.10^{-4} \mathrm{~mol} / \mathrm{l}\right)$ was ineffective on 5-HT-precontracted preparations.

\section{The effect of ER-antagonist on $\boldsymbol{\beta}$-estradiol response}

$17 \beta$-estradiol $\left(10^{-9}\right.$ to $\left.3 \times 10^{-5} \mathrm{~mol} / \mathrm{l}\right)$ caused comparable vasorelaxation in male- and female-derived 5-HT-precontracted rings of HUV (Figure 3). If preparations were pre-treated with the ERantagonist ICI $182,780\left(10^{-7} \mathrm{M}\right.$ for $\left.30^{\prime}\right)$, the concentration-response curves to $17 \beta$-estradiol were significantly shifted to the right in both male- and female-derived HUV. The estimated tissue sensitivity of ICI 182,780 to estrogen receptors, expressed as the $\mathrm{pA}_{2}$ value was comparable in both groups being $(6.87 \pm 0.03)$ and $(6.67 \pm 0.09)$ in male- and female-derived HUV, respectively.

\section{Effect of hesperidin}

Figure 4 shows the concentration-response curves to hesperidin (10 nM- $0.3 \mathrm{mM}$ ) in 5-HT-precontracted preparations. Female-derived HUV exhibited significantly greater vasorelaxations in response to hesperidin $(P<0.01)$ than male-derived tissues. Maximal responses were $(54.0 \pm 4 \%)$ and $(35.0 \pm 5 \%)$ in female- and male-derived tissues, respectively. Pre-treatment with the NO-synthase inhibitor, nitro-Larginine-methyl ester (L-NAME, $10 \mu \mathrm{M}, 30$ '), significantly impaired hesperidin-mediated vasorelaxation $(P<0.01)$ both in male- and 
female-derived rings. The NO component of the hesperidin-mediated vasodilation evaluated as percentage of inhibition induced by L-NAME was more evident in female- than in male-derived tissues. Human umbilical vein rings devoid of endothelium exhibited decreased vasorelaxations in response to hesperidin, which were comparable to those obtained in tissues pretreated with L-NAME. While pre-treated with both L-NAME $\left(10 \mu \mathrm{M}, 30^{\prime}\right)$ and the ATP-sensitive $\mathrm{K}^{+}$channel inhibitor glybenclamide $\left(1 \mu \mathrm{M}, 30^{\prime}\right)$ rings showed a complete lack of response to hesperidin. Furthermore, pinacidil $(1 \mu \mathrm{M})$ an ATP-sensitive $\mathrm{K}^{+}$channel opener, induced vasodilation in 5-HT-precontracted rings (Figure 4).

\section{Effect of diosmin}

Concentration-dependent relaxations to diosmin (10 nM-0.3 $\mathrm{mM}$ ) on 5-HT-precontracted HUV rings were not gender-specific and the two concentration-response curves obtained from male- and

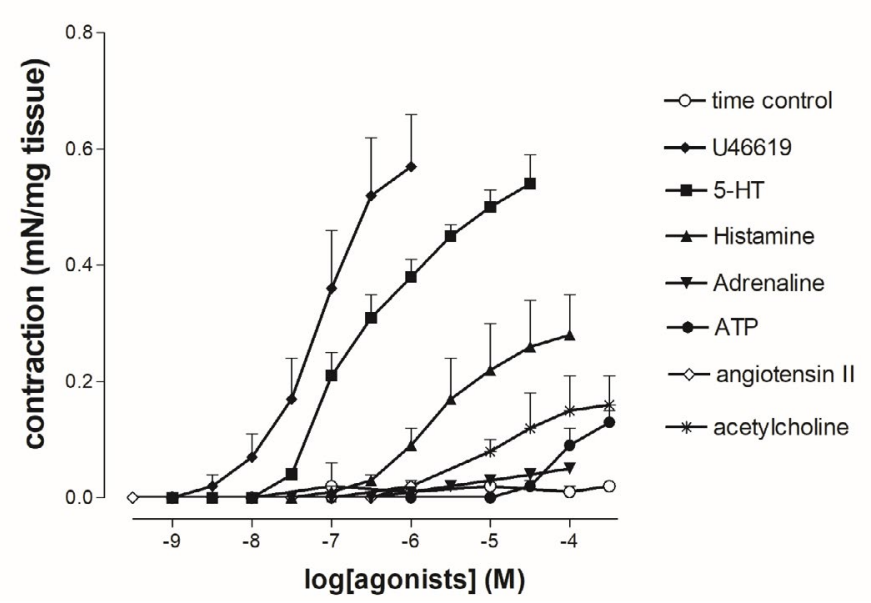

Figure 1. Cumulative concentration-response curves to the stable thromboxane- $\mathrm{A}_{2}$ agonist (U46619), 5-hydroxytryptamine (5-HT), histamine, adrenaline, ATP, angiotensin-II and acetylcholine in rings from female-derived human umbilical vein (HUV) at resting tension. Vasocontractions were expressed as $\mathrm{mN}$ of tension $\mathrm{mg}^{-1}$ wet tissue. Points show mean \pm S.E.M. of 8 experiments, unless occluded by symbol. Statistical significance for curves: ${ }^{*} P$ $<0.05 \mathrm{U} 46619$ vs. 5 -HT; $* * P<0.0055$-HT vs. histamine.

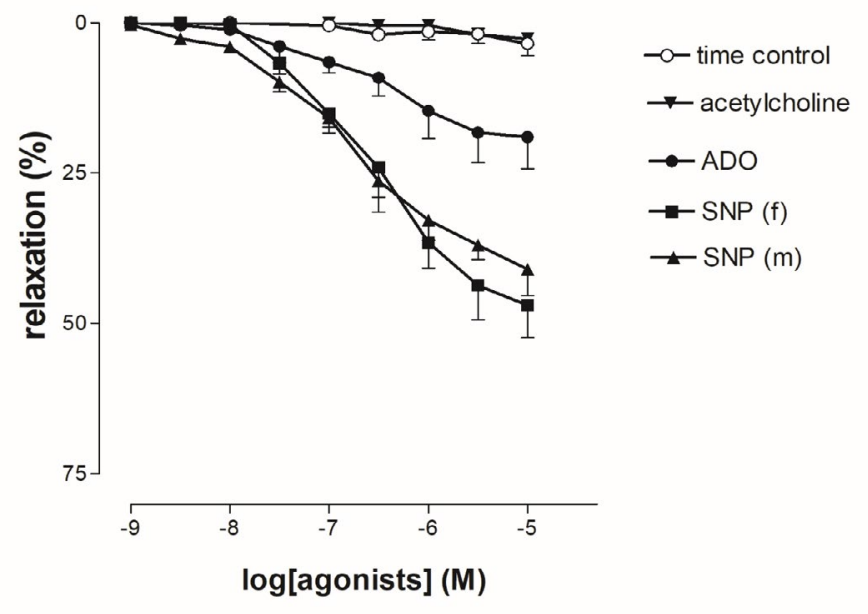

Figure 2. Cumulative concentration-response curves in 5-HT-precontracted rings to acetylcholine (ACh), adenosine (ADO) and sodium nitroprusside (SNP, in female- and male-derived HUV). Vasorelaxations were expressed as percent inhibition of the 5-HTinduced $\left(\mathrm{EC}_{8}\right)$ contraction. Points show mean \pm S.E.M. of 8 experiments, unless occluded by symbol. No significant difference was observed for SNP-induced responses in the female- and male-derived preparations.

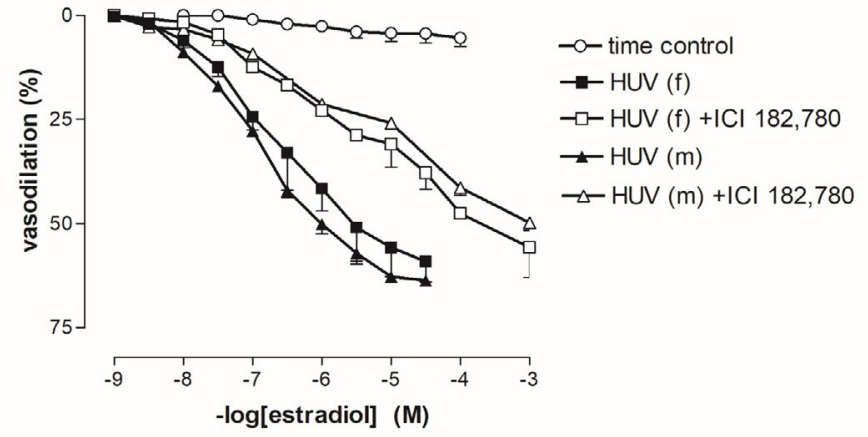

Figure 3. Cumulative concentration-response curves to $17 \beta$-oestradiol in 5-HTprecontracted rings from female- and male-derived human umbilical vein (HUV), before and after incubation with the oestrogen receptor antagonist ICI 182,780. No significant difference was observed between concentration-response curves to $17 \beta$-oestradiol in female- and male-derived groups either before or after the pre-treatment with ICI 182,780. However, pre-incubation with ICI 182,780 significantly shifted to the right $\mathrm{C} / \mathrm{R}$ curves in both groups.

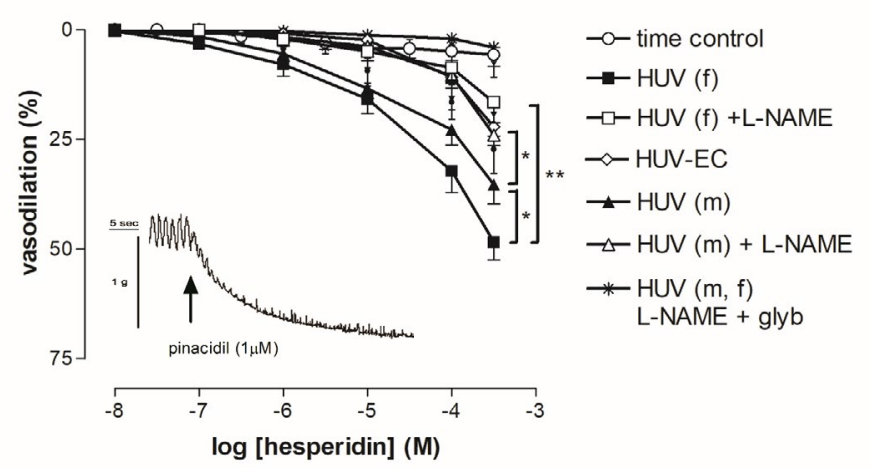

Figure 4. Cumulative concentration-response curves to hesperidin in rings from femaleand male-derived human umbilical vein (HUV). Vasorelaxations were expressed as percent inhibition of the 5-HT-induced $\left(\mathrm{EC}_{80}\right)$ contraction. Points show mean \pm S.E.M. of 8 experiments, unless occluded by symbol. Statistical significance for curves: ${ }^{*} P<0.05$ female-derived vs. male-derived; male-derived vs. male-derived +L-NAME; $* * P<0.005$ female-derived vs. female-derived +L-NAME. The ATP-sensitive $\mathrm{K}^{+}$channel inhibitor, glybenclamide (glyb, $1 \mu \mathrm{M}$ ), completely blocked hesperidin-induced vasorelaxation. Typical tracing of the effect of pinacidil $(1 \mu \mathrm{M})$ in 5-HT-precontracted rings from femalederived HUV (inset).

female-derived preparations did not differ significantly (Figure 5). Maximal responses induced by diosmin in female- $(24.2 \pm 3 \%)$ and male-derived rings $(20.2 \pm 4 \%)$ were significantly weaker than those evoked by hesperidin $(P<0.05)$. Diosmin-induced vasorelaxations were completely suppressed by pre-incubation with L-NAME $(10 \mu \mathrm{M}$, $30^{\prime}$ ) in both groups.

\section{Effect of genistein}

Genistein $(1 \mathrm{nM}-0.1 \mathrm{mM})$ elicited significantly $(P<0.01)$ increased concentration-dependent vasorelaxations in 5-HT-precontracted rings from female- as compared with male-derived HUV. Maximal response was larger in female- $(50.2 \pm 4 \%)$ than in male-derived tissues $(28.9 \pm$ $7 \%)$ and differed significantly $(P=0.02)$. Pre-incubation with L-NAME $(10 \mu \mathrm{M}, 30$ ') in both female- and male-derived tissues impaired genistein-induced vasorelaxation, whereas pre-incubation with both L-NAME $\left(10 \mu \mathrm{M}, 30^{\prime}\right)$ and glybenclamide $\left(1 \mu \mathrm{M}, 30^{\prime}\right)$ completely blocked vasorelaxation (Figure 6).

\section{Discussion and conclusion}

In the present study we observed that hesperidin, and diosmin differed in their responses on HUV preparations; hesperidin elicited 


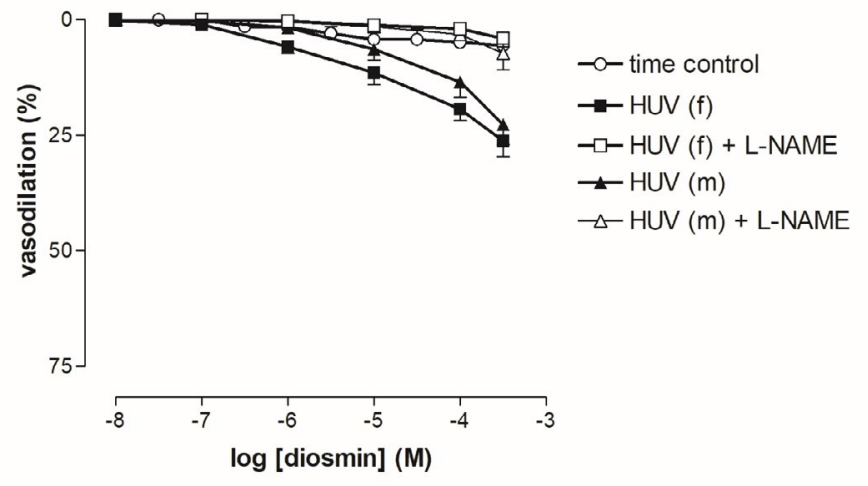

Figure 5. Cumulative concentration-response curves to diosmin in rings from female- and male-derived HUV. Vasorelaxations were expressed as percent inhibition of the 5-HTinduced $\left(\mathrm{EC}_{80}\right)$ contraction. Points show mean \pm S.E.M. of 8 experiments, unless occluded by symbol. Statistical significance for curves: $* P<0.05$ female-derived vs. female-derived + L-NAME and male-derived vs. male-derived + L-NAME.

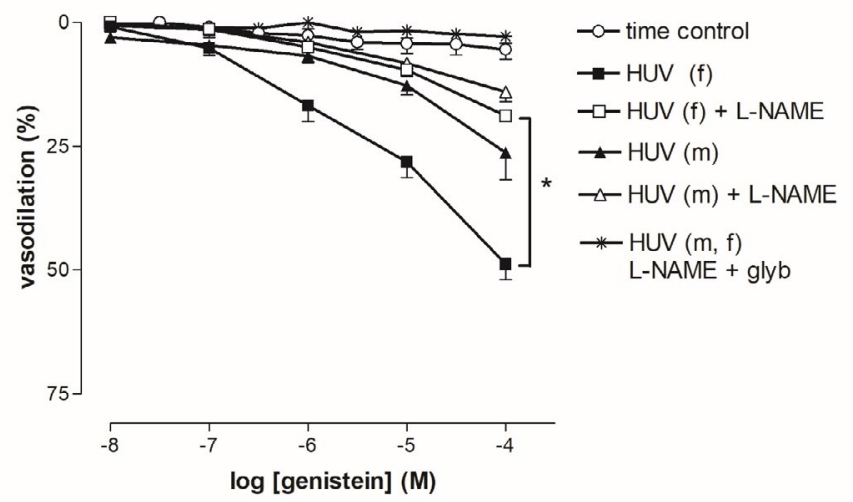

Figure 6. Cumulative concentration-response curves to genistein in rings from femaleand male-derived human umbilical vein (HUV). Vasorelaxations were expressed as percent inhibition of the 5-HT-induced $\left(\mathrm{EC}_{80}\right)$ contraction. Points show mean \pm S.E.M. of 8 experiments, unless occluded by symbol. Statistical significance for curves: ${ }^{*} P<0.05$ female-derived vs. female-derived +L-NAME. The ATP-sensitive $\mathrm{K}^{+}$channel inhibitor, glybenclamide (glyb, $1 \mu \mathrm{M}$ ), completely blocked genistein-induced vasorelaxation.

a significantly larger NO-dependent vasorelaxation than diosmin, comparable to that obtained by the isoflavone genistein.

Previous studies provided evidence that hesperidin induced rapid phosphorylation of eNOS, enhancing its activity and NO production in HUVEC [20]. Hesperidin was also highly involved, more than other Citrus-derived flavonoids, in the blood pressure lowering effects of orange products consumption [21] and a deficiency of hesperidin was associated to capillary leakiness [22]. Not all citrusderived flavonoids were equally effective in inducing eNOS activity; for instance, naringenin (the aglycone form of naringin that remained after hydrolysis of phenolic glycoside) exhibited lower activity than hesperetin (the aglycone form of hesperidin) in HUVEC cells [23].

In our experimental conditions, hesperidin and genistein elicited a significantly wide endothelium-dependent vasodilation in female- than in male-derived HUV rings. The pre-incubation with L-NAME impaired vasodilation to hesperidin and genistein. Residual responses were comparable among male- and female-derived HUV, and in preparations devoid of endothelium. Taken together, these results suggested that

1) the NO component of the hesperidin- and genistein-mediating vasodilation was larger than that of diosmin, and was enhanced in female-derived HUV;
2) hesperidin and genistein induced both endothelium-dependent (through eNOS-NO pathway) and endothelium-independent vasorelaxation. The increased vasodilation induced by hesperidin and genistein in female-derived HUV was not associated to an increased tissue sensitivity to NO, since relaxation to sodium nitroprussiate was not gender-specific. Our observations agreed well with those of Cattaneo et al. [24] who found a sex-specific difference in expression, activity, and function of eNOS in HUVEC.

A sex-specific diversity in response was not limited to umbilical vein; differences in reactivity to vasoconstrictor and vasodilator stimuli, and sex-specific eNOS expression and NO release have also been observed in other vascular beds $[25,26]$.

On the contrary, diosmine evoked a weaker $(25 \%$ at the higher concentration tested) and not gender-specific NO-induced vasorelaxation, which was completely blocked by L-NAME. Supraphysiological concentrations were also required to induce in vitro vasorelaxations to hesperidin and genistein. We assumed that flavonoids such as hesperidin and diosmin, in the form of glycosides, diffused through membranes of endothelial cells less rapidly and less efficiently than their aglycones; alternatively, although maximal care was taken to prepare HUV rings, we could not exclude that a deterioration in the venous blood flow (and thus in the vein endothelium) might occur during labour sometime.

In our experimental conditions, endothelium-independent vasorelaxations in response to hesperidin and genistein were completely blocked by glybenclamide; the presence of smooth muscle ATP-sensitive $\mathrm{K}^{+}$channel was also supported by the observation that pinacidil induced vasorelaxation in our preparations. ATP-sensitive $\mathrm{K}^{+}$ channels are thought to play an important functional role in vascular responses of several vascular beds [27], including HUV [28].

Estrogen receptors (ER) beside their classical function of regulators of gene expression, have been associated to numerous non-genomic functions [29], including the regulatory function of eNOS activity [30]. In our experiments $17 \beta$-estradiol induced not gender-specific vasorelaxation that was antagonized by the ER-antagonist ICI 182,780. Thus, the increased e-NOS activity in female-derived HUV in response to hesperidin and genistein was unlike to be accounted for an estrogenic effect; moreover, comparable levels of steroids, including $17 \beta$-estradiol, have been measured in fetal cord blood from male and female foetuses [31], and studies in twin pregnancies confirmed that maternal serum steroid levels were unrelated to the fetal sex [31]. Further studies would be necessary to elucidate this point; it is possible that the slight difference in chemical structure (hesperidin has saturated pyran ring in their chemical structure, while diosmin has unsaturated pyran ring) might explain the lower activity of diosmin.

Recent observations indicated that placenta was not a barrier for certain polyphenols; indeed, a transplacental transfer of flavonoids, estrogenic isoflavones, and their metabolites in humans [32] have been described.

Despite evidence for beneficial effects of flavonoids- and soy-rich diets in humans, potential adverse effects might occur in response to high flavonoid concentration in placental-fetal circulation [33], or in the case of a high consumption of phytoestrogens [34].

In conclusion, our data suggested that Citrus-derived hesperidin and diosmin may exert beneficial effects on placental circulation through different mechanisms. In particular, hesperidin has been found to be more active then diosmin, especially in female derived HUV. 
Therefore, a regular but moderate consumption (3-4 daily serving) of Citrus fruits, vegetables or orange juice might confer protection to both mother and foetus, reducing blood pressure, and the risk of some fetal vascular complications such as preeclampsia and intrauterine growth restriction.

\section{Acknowledgement}

We are grateful to the clinicians and nurses of Macedonio Melloni Hospital for their assistance in the umbilical cord collection.

\section{References}

1. Pham NM, Do VV, Lee AH (2019) Polyphenols-rich foods and risk of gestational diabetes: a systematic review and meta-analysis. Eur J Clin Nutr 73: 647-656. [Crossref]

2. Habauzit V, Morand C (2012) Evidence for a protective effect of polyphenolscontaining foods on cardiovascular health: an update for clinicians. Ther Adv Chronic Dis 3: 87-106. [Crossref]

3. Hollman PC, Geelen A, Kromhout D (2010) Dietary flavonol intake may lower stroke risk in men and women. $J$ Nutr 140: 600-604. [Crossref]

4. Pistollato F, Sumalla Cano S, Elio I, Masias Vergara M, Giampieri F, et al. (2015) Plant-Based and Plant-Rich Diet Patterns during Gestation: Beneficial Effects and Possible Shortcomings. Adv Nutr 6: 581-591. [Crossref]

5. Oak MH, Auger C, Belcastro E, Park SH, Lee HH, et al. (2018) Potential mechanisms underlying cardiovascular protection by polyphenols: Role of the endothelium. Free Rad Biol Med 122: 161-170. [Crossref]

6. Monsalve B, Concha-meyer A, Palomo I, Fuentes E (2016) Mechanisms of Endothelial Protection by Natural Bioactive Compounds from Fruit and Vegetables. Ann Braz Acad Sci 89: 615-633. [Crossref]

7. Billingsley HE, Carbone S, (2018) The antioxidant potential of the Mediterranean diet in patients at high cardiovascular risk: an in-depth review of the PREDIMED. Nutr Diabetes 8: 13-20. [Crossref]

8. Ly C, Yockell-Lelièvre J, Ferraro ZM, Arnason JT, Ferrier J, et al. (2015) The effects of dietary polyphenols on reproductive health and early development. Hum Reprod Update 21: 228-248. [Crossref]

9. Parlapani E, Agakidis C, Karagiozoglou-Lampoudi T, Sarafidis K, Agakidou E, et al. (2017) The Mediterranean diet adherence by pregnant women delivering prematurely: association with size at birth and complications of prematurity. J Matern Fetal Neonatal Med 13: 1-8. [Crossref]

10. Dobiaš L, Petrová M, Vojtko R, Kristová V (2016) Long-term treatment with hesperidin improves endothelium-dependent vasodilation in femoral artery of spontaneously hypertensive rats: the involvement of NO-synthase and Kv channels. Phytother Res 30: 1665-1671. [Crossref]

11. Constans J, Bennetau-Pelissero C, Martin JF, Rock E, Mazur A, et al. (2015) Marked antioxidant effect of orange juice intake and its phytomicronutrients in a preliminary randomized cross-over trial on mild hypercholesterolemic men. Clin Nutr 34: 10931100. [Crossref]

12. Protić D, Beleslin-Čokić B, Spremović-Rađenović S, Radunović N, Heinle H, et al (2014) The different effects of resveratrol and naringenin on isolated human umbilical vein: the role of ATP-sensitive $\mathrm{K}^{+}$channels. Phytother Res 28: 1412-1418. [Crossref]

13. Achamrah N, Ditisheim A (2018) Nutritional approach to preeclampsia prevention. Curr Opin Clin Metab Care 21: 168-173. [Crossref]

14. Dodd JM, O’Brien C, Grivell RM (2014) Preventing pre-eclampsia - are dietary factors the key? BMC Med 12: 176-178.
15. Nicholson SK, Tucker GA, Brameld JM (2010) Physiological concentrations of dietary polyphenols regulate vascular endothelial cell expression of genes important in cardiovascular health. Br J Nutr 103: 1398-1403. [Crossref]

16. Sastry RBV (1997) Human placental cholinergic system. Bioch Pharmacol 53: 15771586. [Crossref]

17. Chen N, Lv J, Bo L, Li N, Wu C, et al. (2015) Muscarinic-mediated vasoconstriction in human, rat and sheep umbilical cords and related vasoconstriction mechanisms. BJOG 122: 1630-1639. [Crossref]

18. Ludbrook J, (1994) Repeated measurements and multiple comparisons in cardiovascular research. Cardiovasc Res 28: 303-311.

19. Chiou CS, Lin JW, Kao PF, Liu JC, Cheng TH, et al. (2008) Effects of hesperidin on cyclic strain-induced endothelin-1 release in human umbilical vein endothelial cells. Clin Exp Pharmacol Physiol 35: 938-943. [Crossref]

20. Morand C, Dubray C, Milenkovic D, Lioger D, Martin JF, et al. (2011) Hesperidin contributes to the vascular protective effects of orange juice: a randomized crossover study in healthy volunteers. Am J Clin Nutr 93: 73-80. [Crossref]

21. Garg A, Garg, S, Zaneveld LJ, Singla AK (2001) Chemistry and pharmacology of the Citrus bioflavonoid hesperidin. Phytother Res 15: 655-669. [Crossref]

22. Liu L, Xu DM, Cheng YY (2008) Distinct effects of naringenin and hesperetin on nitric oxide production from endothelial cells. J Agric Food Chem 56: 824-829. [Crossref]

23. Cattaneo MG, Vanetti C, Decimo I, Di Chio M, Martano G, et al. (2017) Sex-specific eNOS activity and function in human endothelial cells. J Neurosci Res 95: 398-408. [Crossref]

24. Kunert MP, Dwinell MR, Drenjancevic Peric I, Lombard JH (2008) Sex-specific differences in chromosome-dependent regulation of vascular reactivity in female consomic rat strains from a SSxBN cross. Am J Physiol Regul Integr Comp Physiol 295: R516-R527. [Crossref]

25. Kane MO, Anselm E, Rattmann YD, Auger C, Schini-Kerth VB (2009) Role of gender and estrogen receptors in the rat aorta endothelium-dependent relaxation to red wine polyphenols. Vascul Pharmacol 51: 140-146. [Crossref]

26. Brayden JE (2002) Functional roles of $\mathrm{K}_{\mathrm{ATP}}$ channels in vascular smooth muscle. Clin Exp Pharmacol Physiol 29: 312-316. [Crossref]

27. Protić D, Radunović N, Spremović-Rađenović S, Živanović V, Heinle H, et al. (2015) The Role of Potassium Channels in the Vasodilatation Induced by Resveratrol and Naringenin in Isolated Human Umbilical Vein. Drug Dev Res 76: 17-23. [Crossref]

28. Banerjee S, Chambliss KL, Mineo C, Shaul PW (2014) Recent insights into nonnuclear actions of estrogen receptor alpha. Steroids. 81: 64-69. [Crossref]

29. Mineo, C. and Shaul, P.W. 2012. Regulation of eNOS in caveolae. Adv Exp Med Biol $729,51-62$.

30. Hickey M, Hart R, Keelan JA (2014) The relationship between umbilical cord estrogens and perinatal characteristics. Cancer Epidemiol Biomarkers Prev 23: 946952. [Crossref]

31. Cohen-Bendahan CC, van Goozen SH, Buitelaar JK, Cohen-Kettenis PT (2005) Maternal serum steroid levels are unrelated to fetal sex: a study in twin pregnancies. Twin Res Hum Genet 8: 173-177. [Crossref]

32. Balakrishnan B, Thorstensen EB, Ponnampalam AP, Mitchell MD (2010) Transplacental Transfer and Biotransformation of Genistein in Human Placenta. Placenta 31: 506-511. [Crossref]

33. Barjesteh van Waalwijk van Doorn-Khosrovani S, Janssen J, Maas LM, Godschalk RW, Nijhuis JG, et al. (2007) Dietary flavonoids induce MLL translocations in primary human CD34+ cells. Carcinogenesis 28: 1703-1709. [Crossref]

34. Jargin SV (2014) Soy and phytoestrogens: possible side effects. Ger Med Sci 12: Doc18. [Crossref]

Copyright: (C2019 Pinna C. This is an open-access article distributed under the terms of the Creative Commons Attribution License, which permits unrestricted use, distribution, and reproduction in any medium, provided the original author and source are credited. 